\title{
A intensificação do trabalho docente nas representações sociais de professores
}

Ademir José Rosso*

\begin{abstract}
RESUMO: $\mathrm{O}$ artigo analisa as representações sociais sobre a intensificação do trabalho docente sobre as situações de desgaste, suas formas de apropriação e tradução a partir da experiência vivida por professores na escola. As representações recaem sobretudo no tempo insuficiente e na intensidade no montante de tarefas a serem cumpridas.
\end{abstract}

Palavras-chave: Intensificação da docência. Representação social do trabalho. Condição do trabalho docente.

\section{Introdução}

intensificação do trabalho é descrita nas origens do capitalismo como uma
forma de exploração para escapar das críticas sociais feitas à jornada de tra-
balho (DAL ROSSO, 2006a). O mecanismo, inicialmente descrito na indústria, é ampliado para o trabalho intelectual e o trabalho de serviços (DAL ROSSO, 2006b), entre eles a educação (OLIVEIRA, 2007). Se no passado as estratégias foram de acelerar a maquinaria, remunerar por tarefas e alocar etapas fabris ao espaço doméstico, no presente elas incorporam os mecanismos das tecnologias de comunicação e informação, organizações produtivas e relações trabalhistas que impactam na "vida pessoal e familiar de todos os trabalhadores; sejam eles empregados ou desempregados." (NAVARRO; PADILHA, 2007, p. 19).

Com o mecanismo, o empregador solicita do trabalhador a elevação da quantidade e da qualidade do produto ou serviço. Assim, a intensidade expressa o dispêndio das capacidades dos trabalhadores, sua energia física, inteligência em conceber, criar e

* Doutor em Educação. Professor associado da Universidade Estadual de Ponta Grossa (UEPG), atuando como no estágio supervisionado na Licenciatura de Ciências Biológicas e no Programa de Pós-Graduação em Educação. Ponta Grossa (UEPG). Ponta Grossa/PR - Brasil. E-mail: <ajrosso@uepg.br>. 
analisar, e da afetividade nas relações interpessoais, cultura e socialização (DAL ROSSO, 2006a). Essa crescente demanda de energia intelectual não substitui o gasto de energia física, mas se soma a ela, tornando o trabalho cada vez mais intenso (CARDOSO, 2013).

As pesquisas sobre a intensificação contemplam diferentes formas e condicionantes do trabalho que se expressam e repercutem na vida do trabalhador. A quantidade do trabalho e a sua intensificação passam pela descrição da relação entre as exigências do posto de trabalho e as capacidades e possibilidades de ação num determinado ambiente de trabalho, bem como no contexto macroeconômico e social (ALVES, 2009). Esse olhar rompe com a percepção da intensidade, vinculada apenas à extensão do tempo, ritmo e cadência da produção, acrescentando-lhe novos condicionantes (CARDOSO, 2013).

Como condicionantes que promovem a intensificação, podem-se listar, entre outros: a função ou especificidade (CARDOSO, 2013), a gestão (OLIVEIRA, 2004), o aparato tecnológico, a ergonomia associada à epidemiologia (ASSUNÇÃO; OLIVEIRA, 2009) e a subjetividade tomada pelo trabalho (NAVARRO; PADILHA, 2007). Trata-se de elementos imbricados, mas que serão descritos em separado por didatismo.

Na escola pública, os professores têm ampliado o atendimento de funções que ultrapassam a sua formação e cargo, desempenhando "funções de agente público, assistente social, enfermeiro, psicólogo, entre outras." (OLIVEIRA, 2004, p. 1132). Com essas exigências, a especificidade do ensino é secundada (LELIS, 2012), sumindo-se as peculiaridades das atividades fins e meio, e de hierarquia na execução. Além da quantidade e heterogeneidade das demandas dos alunos e comunidades que aportam à escola, as funções de auxiliar de ensino, bibliotecária, ajudante de secretaria e pedagogo geralmente são exercidas por apenas um profissional, tornando-se comum a ausência de todo esse pessoal de apoio no cotidiano escolar. Esse acréscimo de demanda aos professores pode ser interpretado como perda de controle sobre o seu próprio trabalho e atendimento de expectativas externas ao contexto educativo (ASSUNÇÃO; OLIVEIRA, 2009).

Os dispositivos de gestão por objetivos e metas (FORTINO, 2012), gestão escolar partilhada (GARCIA; ANADON, 2009), constroem exigências numéricas que, além da intensificação no trabalho, tendem a proteger a divisão capitalista do trabalho e da luta de classes (PINA; STOLTZ, 2011), vigiar e reprimir a docência, forçar a cumprir metas em condições desfavoráveis, promover a concorrência, diminuir os postos de trabalho (SILVA; VERÇOSA; BUENO, 2013), criar burocracias para prestação de contas do ensino (SILVA; VERÇOSA; BUENO, 2013), responsabilizar os professores pelo desempenho discente (OLIVEIRA, 2004), fragilizar os docentes objetiva e subjetivamente, empobrecer, desqualificar a docência, bloquear a criatividade dos professores e interferir até mesmo na aprendizagem do aluno (ASSUNÇÃO; OLIVEIRA, 2009). A incorporação da cultura do gerencialismo (RAICHELIS, 2013) esvazia os conteúdos reflexivos e criativos da docência, enquadrando processos e dinâmicas institucionais às metas de controle de qualidade e produtividade. 
O aparato tecnológico advindo da revolução da informática é comparável à revolução industrial (DAL ROSSO, 2006a). Esse aparato poderia aliviar e facilitar as tarefas docentes, mas traz novas imposições e pressões mentais e físicas (FERNANDES, 2011). As tecnologias da informação servem tanto para acionar quanto para controlar os docentes com demandas de trabalho durante o tempo livre, fora da escola. Isso desterritorializa o trabalho docente, aproximando-o do não trabalho (RAICHELIS, 2013), colonizando o espaço e tempo mortos.

As condições fisiológicas e biomecânicas do trabalho em sala de aula expõem fatores de risco enfrentados pelos docentes e traduzem a sua ergonomia. Entre esses fatores está o uso necessário, constante e intensivo da voz, impedindo a recuperação das estruturas fonoarticulatórias. Ainda, o ambiente físico das escolas é "ruidoso, empoeirado, com acústica insatisfatória, de tamanho inadequado, com limpeza precária e realizada com produtos irritativos", com tempos escassos de descanso que tornam trabalho e ambientes estressantes (KARMANN; LANCMAN, 2013).

A percepção do trabalho crescente com a falta de tempo para desenvolver as atividades escolares, obrigando os professores a levarem tarefas para casa. É a captura da subjetividade, a colonização do espaço do não trabalho (RAICHELIS, 2013), do recuo do espaço pessoal e da convivência com grupos de trabalho nos tempos livres (FORTINO, 2012), retroalimentando os estilos de vida e de subjetivação do trabalho (GRISCI, 2003), e subordinando ao trabalho inteligência, capacidades criativas e analíticas, afeto nas relações interpessoais, cultura, socialização e experiências pessoais (CARDOSO, 2013). A subjetividade torna-se, assim, controlada mediante expectativas, pressões, culpas e frustrações impelidas sobre o ser e o fazer na escola e fora dela. Essas práticas burocráticas e discursivas têm autorresponsabilizado e culpado os docentes (OLIVEIRA, 2007) pelas tarefas, desempenho, formação e atualização, e até mesmo pelo sucesso ou fracasso do aluno e da escola (GARCIA; ANADON, 2009).

A intensificação do trabalho é complexa em função da variedade de causas e consequências (CARDOSO, 2013), altera as relações temporais, espaciais, gerenciais, funcionais e subjetivas, pressionando e constrangendo os trabalhadores. A comunidade científica tem produzido uma explicação e detalhamento crescentes, mas os trabalhadores, a partir da vivência da carga de trabalho e da agregação de demandas, produzem e partilham conhecimentos que em alguns textos são chamados de percepção ou, simplesmente, de representação. Essa representação não é mera alienação: ela possui um papel ativo sobre as práticas dos indivíduos e das classes sociais; representa uma construção positiva que não se curva ao controle e que não pode ser tomada como reflexo da realidade, ilusão ou "falsa consciência" (PINA; STOLTZ, 2014), pois há um conhecimento associado aos pertencimentos sociais (LOMBARDI, 1997), articulado aos aspectos simbólicos da realidade.

Esses conhecimentos produzidos pelos trabalhadores são representações sociais (RS) porque reapresentam, atualizam e renovam os significados do trabalho que explora o 
trabalhador. São conhecimentos partilhados, circulantes, não de trabalhadores isolados, mas de categorias que enfrentam a carga de trabalho, as condições que determinam a fadiga e a percepção de ser explorado (MOSCOVICI, 2012). Dessa forma, as representações da intensificação do trabalho são sociais pela cognição dos sujeitos imersos no contexto social e pelos pensamentos entranhados nesse contexto (JODELET, 2007).

As RS sobre a intensificação fazem parte da vida dos docentes. Por se apoiarem na experiência pessoal e na experiência dos trabalhadores contemporâneos (PRAZERES; NAVARRO, 2011), essas representações constituem uma experiência vivida nas esferas subjetiva, intersubjetiva e transubjetiva, sendo, com isso, socialmente construídas (JODELET, 2005, 2007). Dessa forma, a intensificação e seus desdobramentos não são apenas um objeto da ciência, mas de trabalhadores que, no espaço da vida concreta, se debruçam e falam sobre ele, com olhares e validades diversas; buscam o entendimento e o consenso numa alquimia que tenta destilar as verdades. A formação de RS passa pelo mecanismo da ancoragem e da objetivação, e consta das dimensões dos conhecimentos, imagens e atitudes (MOSCOVICI, 2012).

A ancoragem contempla a categorização, comparação, generalização e diferenciação das cognições associadas aos aspectos afetivos, simbólicos e às atitudes. Dessa forma, a intensificação liga-se aos conhecimentos circulantes sobre o trabalho, os quais a traduzem e se aproximam dela, reeditam e transformam, enriquecendo-a de novos elementos que favorecem o entendimento e o consenso na comunicação. A ancoragem permite que o desconhecido seja incorporado às cognições anteriores. Já na objetivação o sujeito busca materializar uma ideia abstrata em algo concreto, traduzindo seus pensamentos em algo existente na natureza. É a conversão de um conceito em imagem, com a visualização do antes disforme. O filme Tempos Modernos, de Chaplin, pode ser uma imagem da intensificação. Nesse processo, corporificam-se as ideias, podendo-se recorrer a metáforas e imagens na descrição do objeto. As metáforas condensam e coordenam significados, operando os núcleos das RS, agenciando os predicados e lugares comuns. O próprio Marx recorreu à imagem de poros para explicitar o não trabalho e a intensificação como diminuição desses poros.

O conhecimento presente numa RS está ligado à experiência e "a um sistema de valores, de noções e de práticas que dão aos indivíduos os meios necessários para se orientar no ambiente social e material." (MOSCOVICI, 2012, p. 28). As imagens manifestam tanto os conhecimentos interiores quanto os conhecimentos do exterior dos sujeitos, servindo para filtrar as mensagens e direcionar a interpretação dos conhecimentos e experiências. O papel das imagens busca reproduzir uma teoria "percorrendo o caminho inverso" ao da ciência, concretizando os conteúdos sem intermediações ou rodeios (MOSCOVICI, 2012, p. 61). As atitudes expressam os posicionamentos em relação a um objeto, acontecimento ou experiências associadas às RS; a predisposição para a ação, prevendo o que o sujeito vai fazer e dizer dentro do contexto social em que o objeto é aprendido; a 
orientação psíquica favorável ou desfavorável "revelada por um comportamento global ou por uma série de reações cuja significação é comum." (MOSCOVICI, 2012, p. 445).

As três dimensões da RS da intensificação do trabalho docente - conhecimento, imagens e atitudes - fornecem uma visão de conjunto do seu conteúdo e sentido. Os elementos que intensificam o fazer pedagógico são convertidos em relação aos valores e imagens que se fixam na realidade social como um corpo natural de conhecimentos. Assim, analisar a intensificação da docência como RS significa buscar as formas da sua apropriação, transformação e tradução a partir da experiência vivida na escola.

\section{Informações coletadas e análises}

As informações analisadas derivam de pesquisa sobre a intensificação do trabalho docente, que foi desenvolvida em duas etapas: em 2010, com a realização de 38 entrevistas; e em 2012, com mais 42 entrevistas. As entrevistas foram semiestruturadas, antecedidas de triagens sucessivas sobre as situações que desgastam os docentes. Do total das entrevistas, 35 informantes comentaram situações promotoras da intensificação do trabalho docente, entre as quais estavam os problemas das salas lotadas, o excesso de atividades e carga horária. A partir desse recorte formou-se o corpus intensificação.

Dos informantes, oito foram homens e 27 mulheres; nove tinham menos de 30 anos, 14 tinham de 31 a 40 anos, a idade de outros nove estava entre 41 a 50 anos, e havia três professores com mais de 51 anos; dez docentes eram contratados temporários e 25 eram efetivos; 12 possuíam filiação sindical e 23 não; dez professores estavam a menos de cinco anos no magistério, nove tinham de seis a dez anos na profissão, oito tinham de 11 a 15 anos e outros oito estavam no magistério há mais de 15 anos; três professores não eram licenciados, os demais tinham licenciatura e, entre eles, havia cinco com pós-graduação strito senso; um professor declarou ter menos de 20 alunos em sala, quatro professores tinham até 30 alunos, 23 tinham até 40 e sete afirmaram ter mais de 40 alunos em sala; desses professores, oito tiravam licença para tratamentos de saúde decorrentes da docência.

O corpus intensificação foi processado pelo software Alceste, promovendo a análise lexical do conjunto de segmentos com uma dimensão quantitativa dos elementos textuais. O referido corpus originou cinco classes. As classes 1 e 2 descrevem elementos de intensificação associados ao processo de ensino e aprendizagem - salas lotadas e sua organização; e as demais classes falam sobre o tempo para execução das atividades associadas ao salário. A apresentação das classes a partir das suas localizações no dendograma parte da esquerda para a direita (Figura 1). 


\section{Figura 1 - Corpus intensificação}

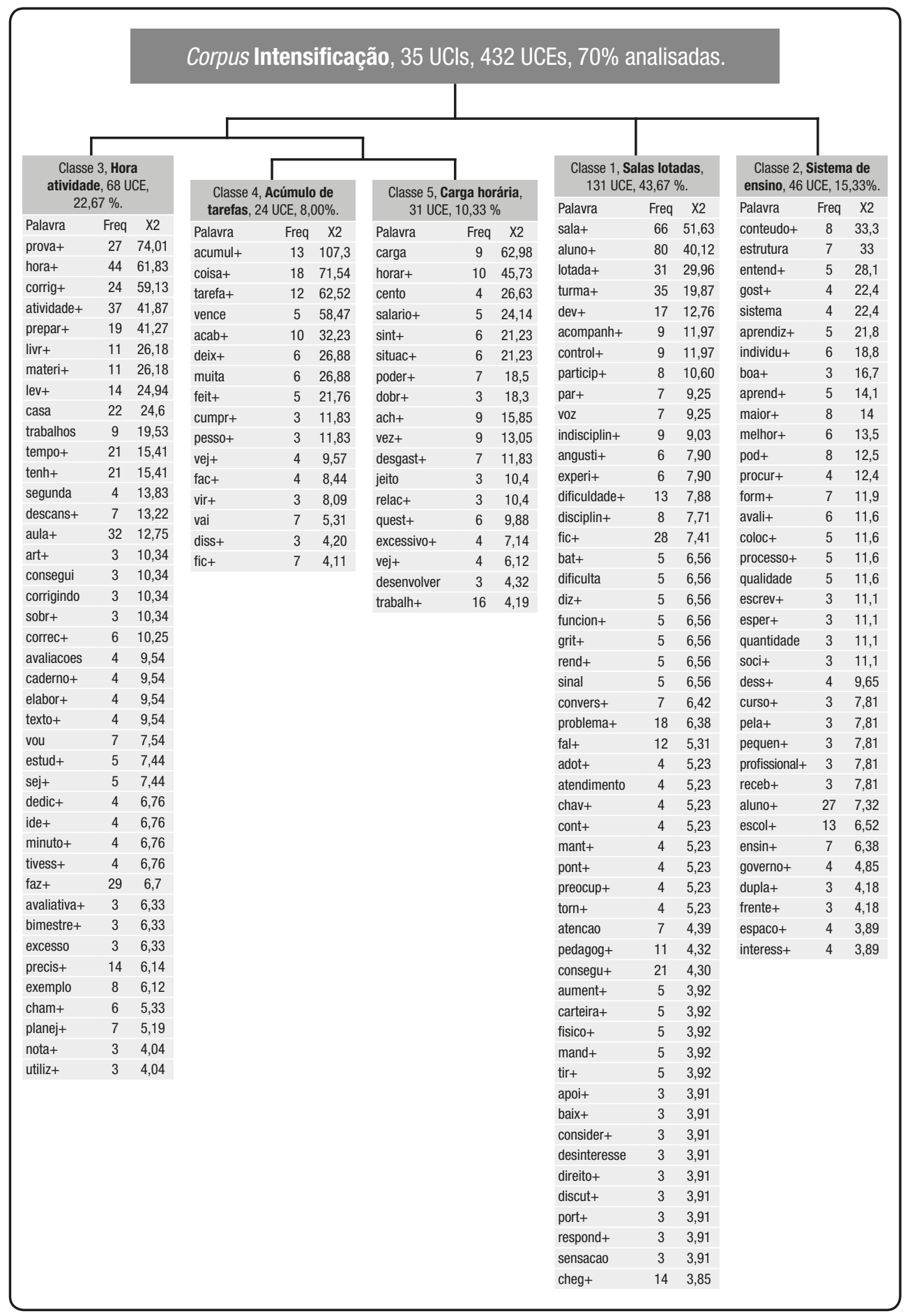

Fonte: $\mathrm{O}$ autor. 
A classe 3, hora atividade, recebeu contribuição diferenciada dos licenciados que não tiravam licença de saúde, homens e faixa etária de até 30 anos. Os objetos da classe são provas, materiais didáticos, trabalhos de alunos, cadernos de chamada, notas bimestrais, planejamento e estudo. As atividades a eles associadas são corrigir, preparar, levar para casa como obrigação - tenho que, é preciso (o dever); e as dificuldades dos docentes estão relacionadas, sobretudo, à utilização do tempo doméstico para a realização das tarefas complementares às aulas, frente à falta de tempo e infraestrutura, na escola, para isso. Os entrevistados listaram algumas atividades essenciais que a hora atividade não cobre, como o estudo, a preparação de aulas, a elaboração de material didático e avaliações, a correção das atividades de sala de aula, trabalhos e provas, o preenchimento dos cadernos de chamada e, ainda, o atendimento das demandas de atualização e formação continuada.

Para contornar as limitações, os professores levavam trabalho para casa, a fim de fazer "depois [...] [de] atender os filhos, descansar um pouco e preparar a janta." Também, elaboravam provas de fácil correção, aplicadas em duplas ou grupos, organizavam atividades para serem avaliadas pro forma e usavam os finais de semana para fazer as atualizações. Dois depoimentos traduzem a situação da hora atividade: "Não tenho tempo para preparar aulas, [...] material [didático], nem para elaborar prova, no máximo [tempo] para corrigir e para atualizar livro de chamada"; "Não posso fazer tudo aqui na escola [...], preciso levar trabalhos para corrigir em casa, aos sábados e domingos." Dessa forma, a hora atividade configura-se numa falsa melhoria das condições de trabalho, pois mantém os professores presos ao trabalho e sem condições de executar o que deles é cobrado nesse horário (PINA; STOLTZ, 2011).

A classe 4, acúmulo de tarefas, recebeu contribuições dos informantes com mais de 50 anos de idade e mais de 15 anos de magistério; efetivos; especialistas; do sexo feminino e, com menor peso, do sexo masculino; e atuantes em turmas de até 40 alunos. A classe destaca as dificuldades encontradas na docência, focalizando o montante de atividades e o esforço necessário para vencê-las. Algumas expressões provam essa relação, como, por exemplo: "são muitas tarefas num determinado tempo" ou "mais coisas para fazer do que condições e tempo para fazê-las", e novamente as atividades excedentes tornavam-se "trabatho a ser feito em casa, [pois] a hora atividade não cobre." Como consequência, os professores acabavam "deixando de lado os compromissos de casa", o que redundava em arrependimento. Assim a intensificação, percebida no acúmulo de atividades, aumenta a degradação e a exploração do trabalho, expressando a adoção pelo empregador da redução "do trabalho pago e ampliação do trabalho excedente." (RAICHELIS, 2013, p. 623).

Essa pressão gerava um débito permanente, pois "por mais que faça tudo certinho, [...] ainda alguma coisa fica para fazer"; "algumas delas serão malfeitas, [...] gerando insatisfação". Nos termos de uma informante, o acúmulo de atividades causava "estresse, [por] estar correndo atrás e vendo as coisas"; outra depoente afirmou: "fico ansiosa, com falta de ar, me 
sinto péssima". Professores com mais tempo de magistério falaram sobre "problemas de saúde que vão surgindo". Quando chegava o final do ano ou bimestre, "dói tudo, as costas, o pescoço, a cabeça, não tem o que não doa". Situações vivenciadas pelos docentes são comparadas com algumas apresentadas no citado filme Tempos Modernos, em que se tem "um planejamento e um tempo para executar e tem que acelerar, pois tem muita coisa para ser feita." Desprendem-se da classe os efeitos do aumento de demandas físicas e psicossociais pelo aumento e ritmo de atividades na docência (LOMBARDI, 1997; GRISCI, 2003; FERNANDES, 2011).

A classe 5, carga horária, recebeu contribuições de professores que tiraram licença para tratamento de saúde, com carga horária elevada, efetivos, sindicalizados e que declararam ter em média mais de 30 alunos em sala de aula. O foco dessa classe é a carga horária e os desgastes correspondentes, contrapostos ao salário recebido. A primeira percepção está na falta de tempo, ou de que não se é ágil e organizado o suficiente. Na fala de uma informante, "você sempre está atrasada em relação ao que você gostaria de desenvolver."

O contraponto do salário é expresso na fala: "O governo cobra [...], enfia [...] carga horária em um salário pequeno [...]. Se trabalhar vinte horas ganha pouquinho [...], então para melhorar o salário tem que dobrar a carga horária." Mais uma fala reforça esse argumento: "Se aceito a pressão de uma carga horária é por necessidade, não pela convicção de estar executando um trabalho de qualidade." Assim, o trabalho excessivo é uma escolha constrangida, feita no início da carreira pela pressão salarial, que só melhora depois de muito tempo (ALVES, 2009). Declarou um informante: "A minha situação é de trabalho escravo mesmo, ou trabalho tudo isso ou não como." Se não bastasse os docentes se sentirem culpados e declararem que poderiam fazer muito mais, eles afirmaram, contraditoriamente, que trabalhar mais de 40 horas é "uma questão particular".

Tanto o fenômeno da simplificação didática e de ignorar as demandas dos discentes para poderem se manter na rotina, como outras situações de cunho defensivo com modulação do esforço foram relatados pelos professores. O livro didático foi justificado como estratégia, pois se "não conseguir preparar uma aula do jeito que desejaria, tem exercício no livro." A situação foi justificada por outro informante: "Não é malandragem, é para chegar ao final do semestre e poder respirar, sem cair num estresse violento." Se nas classes anteriores os elementos promotores da intensificação do trabalho estavam na insuficiência da hora atividade, a pressão foi do salário que submetia os docentes a uma carga horária que desqualifica a docência. Na fala de um professor: "Meu sonho é [...] que pagassem salários dignos para que pudéssemos desenvolver um trabalho de qualidade."

A classe 1, salas lotadas, refere-se às salas ou turmas com grande quantidade de alunos, destacando os problemas daí decorrentes para o desenvolvimento das atividades docentes. A intensificação sobressaiu pela sua associação com o número de alunos a serem atendidos e as demandas decorrentes. A origem das informações da classe ficou associada aos elementos que descrevem os informantes, em ordem decrescente: número 
de alunos (mais de 40 por sala de aula), mais de 15 anos de atuação no magistério, idade entre 31 a 40 anos, sexo feminino, trabalho em escolas da rede estadual e particular.

Segundo os informantes, as salas lotadas interferiam nos procedimentos didáticos, os quais se tornavam verticalizados; as atividades eram realizadas apressadamente, sem os feedbacks necessários; evitavam-se atividades em grupo, dispondo-se os alunos em fileiras. Nas palavras de um informante, "o professor se torna centralizador e chato, porque está sempre chamando atenção." Como as salas lotadas favoreciam a dispersão e o murmúrio, a condução disciplinar aliava-se a procedimentos de controle. Sobre essa situação, depôs um professor: "Em salas lotadas são comuns as conversas paralelas, a falta de atenção; quando os professores falam, os alunos não escutam." No atendimento dos alunos que necessitavam de atenção diferenciada era difícil de identificá-los e acompanhá-los durante as aulas, deslocar-se entre as carteiras e até trazê-los à frente para apoiá-los. Disse uma professora que o problema "está na angústia enfrentada de não conseguir atender aqueles alunos que precisariam mais." A saúde dos professores que necessitavam de um esforço adicional de voz, falando muito alto, ficava comprometida. Nas palavras de uma professora, "é terrível [...] devemos falar muito alto"; e ela completou: "perco com facilidade a voz, já tenho um problema grave, de gritar muito."

Assim como a carga horária foi a via adotada pelos professores para falar dos baixos salários, as salas lotadas aumentavam a taxa de "exploração do trabalho docente, tendo em vista a intensificação do trabalho a ser realizado no mesmo período." (KARMANN; LANCMAN, 2013, p. 169). A consequência disso pode ser sintetizada na fala de um professor: "[...] porque você deve retroceder no que você pensa de prática pedagógica para ter o controle da turma e fazer atividades extremamente conservadoras e tradicionais como questionários e ditar textos." Depreende-se dessa classe que com o aumento de alunos em sala de aula crescem os sistemas de controle didático. Um dos informantes relatou a junção de turmas, que numa única operação promoveu a dispensa dos professores não concursados, sobrecarregou os demais professores e gerou descontentamento dos alunos. Enfim, o discurso do melhor aproveitamento de recursos materiais e humanos em proveito da intensificação do trabalho docente pressupõe resistências e adoecimentos (DAL ROSSO, 2006a).

A classe 2, sistema de ensino, recebeu contribuição diferenciada, em ordem decrescente, de professores que atendiam turmas de até 30 alunos, possuíam mestrado e eram sindicalizados. Essa classe traz produções discursivas sobre a escolarização, o que os alunos aprendem e o que se cobra dos docentes nas práticas formativas e discursivas do sistema de ensino - o ensino como um processo individualizado. No contraponto da classe, destacam-se os conflitos advindos do sistema com suas normas e discursos, da formação docente e teorias educativas, da infraestrutura da escola e recursos materiais disponíveis, das rotinas de trabalho e mecanismos de controle estabelecidos frente às funções que os professores devem executar. 
Um informante chamou a atenção para o conflito de classes, em que o professor "não tem noção do espaço em que trabalha e se coloca acima de todos [...], [culpa o aluno] pelo fracasso sem pensar no sistema em que vive e na estrutura social a que estamos sujeitos." Esse depoimento retrata a contradição entre a formação docente do tipo liberal e o exercício profissional assalariado (MARTINS, 2008). No sistema educacional o maior conflito, ou ideologia (ALVES, 2009), está em exigir "uma formação complexa, humana [...] [e avaliar dentro de] uma lógica quantitativa, estritamente matemática, exata." Contrapõem-se a essas exigências as questões estruturais que dificultavam a gestão disciplinar, atividades pedagógicas diferenciadas e em locais alternativos pelo número elevado de alunos e espaços reduzidos. Nas palavras de um docente, "o sistema insiste em pedir números [desempenho], [sem] dar estrutura [...], construir escolas." Em relação ao princípio de incluir na escola regular alunos com necessidades especiais, teve a seguinte manifestação: "Até consigo entender que o aluno está aqui na escola, o objetivo maior é que ele fique aqui [...], porém deveríamos receber os recursos." Juntam-se a ideologia da educação humanizadora e os resultados e funcionamento em padrões gerenciais para responsabilizar os educadores pela qualidade do serviço prestado (ASSUNÇÃO; OLIVEIRA, 2009). Nessas condições e nas ligadas à pressão do tempo, os professores ajustavam os mecanismos de avaliação para "dar conta da correção [...] e não para melhorar o aprendizado dos alunos."

As informações processadas sobre o conhecimento prático da intensificação manifestaram uma cisão entre a duração temporal da docência - carga horária e hora atividade -, correspondendo a 33\% do corpus analisado, e a dimensão da intensidade - acúmulo de tarefas, salas lotadas e sistema de ensino -, correspondendo a 67\% do corpus analisado. Tais informações e os resultados delas decorrentes implicam um posicionamento, um ponto de vista contrário ao de Cardoso (2013), que relata ser a dimensão temporal a mais esperada dos informantes, e a de intensificação a menos reconhecida. Os componentes da intensificação formulados pelos pesquisadores sobre as relações que os sujeitos estabelecem com o trabalho diferem das "dimensões reconhecidas na vida cotidiana". Os conhecimentos da experiência cotidiana satisfazem a necessidade de promover "comportamentos ou visões socialmente adaptados ao estado dos conhecimentos sobre o real." (MOSCOVICI, 2012 p. 72). Esses conhecimentos e confabulações atravessam o cotidiano e associam-se a estudos, à participação em mobilizações da categoria e da mídia. Dos 80 entrevistados, 35 apresentaram elementos de intensificação sem serem questionados diretamente sobre o tema, elementos estes que atestam a sua vivência pulsante.

A compreensão dimensional das RS compreende a integração dos conhecimentos, imagens e atitudes (MOSCOVICI, 2012). Os conhecimentos circulantes foram analisados a partir dos relatórios emitidos pelo Alceste e apontaram as classes que apresentamos. Agora nos detemos nos elementos que escapam à análise lexical e necessitam da análise de conteúdos, pois aparecem ao longo das informações como sinalizadores do que extrapola a linguagem convencional. São as atitudes e as imagens. 
Entre as atitudes estão as de revolta, conformismo, arrependimento, débito, voluntarismo e sacrifício. Revolta em ter que submeter o espaço e o tempo privado em favor do trabalho, e ver que a condução do processo educativo está muito longe do que se propõe e submetida a princípios de gestão (OLIVEIRA, 2007). Associado à revolta está o conformismo de, pelo menos, conseguir controlar a turma, com menos eficiência, ou só executando o mínimo diante das turmas lotadas ou da diversidade encontrada na escola, e adotar um modelo pedagógico controlador. Arrependimento em sacrificar o convívio familiar e o descanso em favor de um trabalho que nem sempre tem retorno financeiro e satisfação pessoal (HIRATA, 2009). Sentimento de permanente débito por não conseguir atender todos os alunos e suas especificidades, controlar o tempo, cumprir o planejamento, estudar e atualizar-se, executar as tarefas e dar um retorno adequado aos alunos (KARMANN; LANCMAN, 2013). Para fazer frente às crescentes exigências sobressai o voluntarismo (OLIVEIRA, 2004) de "dar conta", "custe o que custar", situação que remete ao sacrifício do professor ao assumir uma jornada que ultrapassa as suas condições em troca de um salário razoável. Como disse um entrevistado, "não é para bonito, [mas] porque eu preciso." Uma atitude declarada é a de impotência (PINA; STOTZ, 2014; ASSUNÇÃO; OLIVEIRA, 2009), "porque sobram tarefas e falta tempo", e o que advém disso, segundo um informante, são "os sentimentos de fracasso". Ante as estratégias defensivas, um professor afirmou: "Não é malandragem, é para chegar ao final do semestre e poder respirar, se cair num estresse violento eles não terão nem professor."

A experiência pessoal da intensificação é expressa na imagem de asfixia, de perder o ar, sentir-se sufocado. Com "menos horas e mais alunos, acaba sufocando, exigindo um trabalho mais acelerado que gera sofrimento porque o tempo passa sem a gente sentir" (grifo nosso). Passar o tempo sem sentir é uma das causas diretas da alienação ou estranhamento frente ao ritmo acelerado e demandas crescentes (NAVARRO; PADILHA, 2007). A captura da subjetividade (ALVES, 2009; GARCIA; ANADON, 2009) é expressa nas imagens de invisibilidade, manifestada da seguinte forma: o trabalho da escola "não termina quando bate o sinal [...], vai junto para casa", "misturando as coisas". E o sofrimento está em "executar um trabalho invisível que não recebo para fazer".

Sobre o trabalho docente (excessivo!), o autorretrato é de "uma pessoa [...] com uma carga pesada nos ombros para sobreviver", pois o "trabalho excessivo acaba com a vida do professor." O professor é um "coitado no meio de um monte de tarefas para fazer e não sabe por onde começar". Sobre a condução do seu trabalho, um informante recorreu à imagem de estar "em um barco, remando contra o vento e você não [...] ir para onde você quer." "É vida de escravo puro, cobranças mil [...] você trabalha tudo isso ou não come." São imagens da perda de segurança, autonomia; da corrosão da autoestima e realização pessoal e profissional (KARMANN; LANCMAN, 2013).

A compreensão sobre a relação temporal é diferenciada (GRISCI, 2003; FERNANDES, 2011), com imagens materiais de fluidez, como "um relógio muito acelerado, uma 
ampulheta com o último grãozinho de areia", chegar atrasado ao ponto de ônibus em que "você viu ele te deixando para trás, e você sabe que você tem que chegar no horário no trabalho [...]. Você sempre está atrasada em relação ao que você gostaria de desenvolver." Outro informante se reportou a Salvador Dali, importante pintor catalão: "Naquela paisagem dele, calor excessivo, os relógios derretendo como se o tempo sempre estivesse escoando. Eu sempre tenho que estar correndo atrás, sempre está acabando e sempre fica alguma coisa."

Sobre a gestão e a escola e seus mecanismos de controle, usou-se a expressão "sem pé e nem cabeça [...] e não tem nada a ver"; sobre as iniciativas improvisadas (ASSUNÇÃO; OLIVEIRA, 2009) utilizou-se a "filosofia da gambiara", que não possibilita "boas condições de trabalho". Na mesma direção, a hora atividade considerada como benefício aos professores "é aquele refresco momentâneo", que "passa num abrir e piscar de olhos". A forma de avaliação feita pela gestão da escola é comparada a de um supermercado: "Você tem que medir uma escola pela quantidade de clientes aos quais ela atende."

\section{Considerações finais}

A intensificação do trabalho foi representada pelos professores em cognições que reconhecem o desgaste enfrentado, a possibilidade de executar o trabalho com mais qualidade em outras condições materiais e justificam as iniciativas defensivas para enfrentarem as contingências. A ancoragem expressou-se em modelos idealistas e subjetivistas da docência (TONUS, 2013). Idealistas, ao analisar os resultados alcançados da ação pedagógica; e subjetivistas frente às contingências experimentadas. Essa ancoragem aponta para a contradição entre formação docente socialmente idealizada e liberal com a condição de assalariado (MARTINS, 2008).

Associaram-se a essa ancoragem as objetivações expressas nas imagens do tempo deformado e fluído que escapa à compreensão e controle pessoais, e da intensidade como maquinaria que controla e retira as condições materiais, esvanecendo as atividades executadas no âmbito privado, sem remuneração pelo sistema e nem reconhecimento social. Tais imagens convergem para o lembrado (por um informante) castigo diário de Sísifo, personagem da mitologia grega, de empurrar montanha acima uma pedra gigante que, quando chega ao topo, rola montanha abaixo, fazendo com que, no dia seguinte, Sísifo seja obrigado a repetir o infortúnio.

Frente à submissão constrangida e permanente do trabalho intensificado, as atitudes expressaram revolta, conformismo, arrependimento, débito, voluntarismo e sacrifício. Atitudes defensivas associam-se à modulação do esforço, a processos didáticos econômicos, e à redução de atividades e da qualidade das avaliações. $\mathrm{O}$ arrependimento estava em querer fazer o certo, comprometer-se com os educandos e querer ir além, pagando o preço por trabalhar mais sem remuneração. O débito estava em olhar para o convívio 
familiar e perceber que não se dedicava o suficiente aos seus familiares. O voluntarismo estava em cumprir com os compromissos a qualquer custo. O sacrifício está em colocar a sobrevivência à frente da realização pessoal e profissional. Recorrendo a imagens, as atitudes expressam o dito popular "se correr o bicho pega e se ficar o bicho come".

O alinhamento dos conhecimentos, imagens e atitudes conduzem-nos a duas RS. A primeira, temporal, compreende o tempo em sua linearidade como insuficiente, ou de dedicar-se ao trabalho num tempo que ultrapassa as forças e capacidades pessoais. A segunda, de intensidade, está no montante de tarefas, dos alunos atendidos e das pressões e demandas advindas dos sistemas com seus mecanismos de controle e acréscimo de novas funções.

A qualidade da docência, aquém da necessária e possível, é constantemente lembrada como renúncia em nome do cumprimento de tarefas e metas nem sempre educativas. $\mathrm{O}$ certo é que essa situação não deriva do processo formativo, mas se enraíza na materialidade do trabalho docente. Com a intensificação do trabalho decente, dentro das relações trabalhistas, o preço é pago pelo próprio Sistema Público de Educação no seu todo e seus destinatários - os filhos dos trabalhadores -, não somente os docentes.

Recebido em fevereiro de 2016 e aprovado em abril de 2016

\section{Referências}

ALVES, Giovanni. Trabalho e reestruturação produtiva no Brasil neoliberal: precarização do trabalho e redundância salarial. Rev. Katálysis, v. 12, n. 2, p. 188-197, dez. 2009.

ASSUNÇÃO, Ada Ávila; OLIVEIRA, Dalila Andrade. Intensificação do trabalho e saúde dos professores. Educ. Soc., v. 30, n. 107, p. 349-372, ago. 2009.

CARDOSO, Ana Claudia Moreira. Organização e intensificação do tempo de trabalho. Soc. Estado, v. 28, n. 2, p. 351-374, ago. 2013.

DAL ROSSO, Sadi. Intensidade e imaterialidade do trabalho e saúde. Trab. Educ. Saúde, v. 4, n. 1, p. 65-92, mar. 2006a.

Jornada de trabalho: duração e intensidade. Cienc. Cult., v. 58, n. 4, p. 31-34, dez. 2006 b.

FERNANDES, Rita de Cássia P. Precarização do trabalho e os distúrbios musculoesqueléticos. Cad. CRH, v. 24, n. spe1, p. 155-170, 2011.

FORTINO, Sabine. Processo de vulnerabilização e danos ao ofício: a modernização do trabalho em questão. Rev. Bras. Saúde Ocup., v. 37, n. 126, p. 213-224, dez. 2012.

GARCIA, Maria Manuela Alves; ANADON, Simone Barreto. Reforma educacional, intensificação e autointensificação do trabalho docente. Educ. Soc., v. 30, n. 106, p. 63-85, abr. 2009. 
GRISCI, Carmen Lígia Iochins. Dos corpos em rede às máquinas em rede: reestruturação do trabalho bancário e constituição do sujeito. Rev. Adm. Contemp., v. 7, n. 1, p. 87-108, mar. 2003.

HIRATA, Helena. A precarização e a divisão internacional e sexual do trabalho. Sociologias, n. 21, p. 24-41, jun. 2009.

JODELET, Denise. Experiências e representações sociais. In: MENIN, Maria Suzana S.; SHIMIZU, Alessandra M. Experiência e representação social: questões teóricas e metodológicas. São Paulo: Casa do Psicólogo, 2005. p. 23-56.

. Imbricações entre representações sociais e intervenção. In: MOREIRA, Antonia Silva Paredes; CAMARGO, Brígido Vizeu. (Orgs.). Contribuições para a teoria e o método de estudo das representações sociais. João Pessoa: UFPB, 2007. p. 45-74.

KARMANN, Delmira de Fraga; LANCMAN, Selma. Professor: intensificação do trabalho e o uso da voz. Audiol. Commun. Res., v. 18, n. 3, p. 162-170, 2013.

LELIS, Isabel. O trabalho docente na escola de massa: desafios e perspectivas. Sociologias, v. 14, n. 29, p. 152-174, abr. 2012.

LOMBARDI, Maria Rosa. Reestruturação produtiva e condições de trabalho: percepções dos trabalhadores. Educ. Soc., v. 18, n. 61, p. 64-87, dez. 1997.

MARTINS, Pura Lúcia Oliver. Didática teórica, didática prática: para além do confronto. 9. ed. São Paulo: Loyola, 2008.

MOSCOVICI, S. A psicanálise, sua imagem e seu público. Petrópolis: Vozes, 2012.

NAVARRO, Vera Lucia; PADILHA, Valquíria. Dilemas do trabalho no capitalismo contemporâneo.

Psicol. Soc., v. 19, n. spe, p. 14-20, 2007.

OLIVEIRA, Dalila Andrade. A reestruturação do trabalho docente: precarização e flexibilização. Educ. Soc., v. 25, n. 89, p. 1127-1144, dez. 2004.

Política educacional e a re-estruturação do trabalho docente: reflexões sobre o contexto Latinoamericano. Educ. Soc., v. 28, n. 99, p. 355-375, ago. 2007.

PINA, José Augusto; STOTZ, Eduardo Navarro. Participação nos lucros ou resultados e banco de horas: intensidade do trabalho e desgaste operário. Rev. Bras. Saúde Ocup., v. 36, n. 123, p. 162-176, jun. 2011.

. Intensificação do trabalho e saúde do trabalhador: uma abordagem teórica. Rev. Bras. Saúde Ocup., v. 39, n. 130, p. 150-160, dez. 2014.

PRAZERES, Taísa Junqueira; NAVARRO, Vera Lucia. Na costura do sapato, o desmanche das operárias: estudo das condições de trabalho e saúde das pespontadeiras da indústria de calçados de Franca, São Paulo, Brasil. Cad. Saúde Pública, v. 27, n. 10, p. 1930-1938, out. 2011.

RAICHELIS, Raquel. Proteção social e trabalho do assistente social: tendências e disputas na conjuntura de crise mundial. Serv. Soc. Soc., n. 116, p. 609-635, dez. 2013.

SILVA, Maria Aparecida de Moraes; VERÇOZA, Lúcio Vasconcellos de; BUENO, Juliana Dourado. A imagem do etanol como "desenvolvimento sustentável" e a (nova) morfologia do trabalho. Cad. CRH, v. 26, n. 68, p. 253-271, ago. 2013.

TONUS, Karla Paulino. Psicologia e educação: repercussões no trabalho educativo. Psicol. Esc. Educ., v. 17, n. 2, p. 271-277, 2013. 


\section{The intensification of teaching in the social representations of teachers}

ABSTRACT: The article analyzes the social representations made concerning the intensification of teaching, burn out, and the ways in which it manifests and translates into the lived experience of teachers in schools. The representations are concerned especially with the insufficient time for, and the intensity of the volume of work to be completed.

Keywords: Teaching intensification. Social representations of work. Teaching conditions at work.

\section{L'intensification du travail d'enseignement dans les représentations sociales des professeurs}

RÉSUMÉ: L'article analyse les représentations sociales relatives à l'intensification du travail d'enseignement, aux situations d'usure, leurs formes d'appropriation et de traduction à partir de l'expérience vécue des professeurs à l'école. Les représentations pointent surtout le temps insuffisant et l'intensité de la quantité de tâches à effectuer.

Mots-clés: Intensification de l'enseignement. Representation sociale du travail. Condition de l'enseignement.

\section{La intensificación del trabajo docente en las representaciones sociales de los profesores}

RESUMEN: El artículo analiza las representaciones sociales de la intensificación del trabajo docente, de las situaciones de desgaste, sus formas de apropiación y traducción, a partir de la experiencia vivida por profesores en la escuela. Las representaciones recaen especialmente en el tiempo insuficiente y en la intensidad de las tareas a llevar a cabo.

Palabras clave: Intensificación de la docencia. Representación social del trabajo. Condición del trabajo docente. 